\title{
Electron Energy Loss Spectroscopy Study of Li in Lithiated FeOF/C Nanocomposite Battery Material
}

\author{
K.S. Rao ${ }^{1}$, N. Pereira ${ }^{1,2}$, G. G. Amatucci ${ }^{1,2}$ and F. Cosandey ${ }^{1}$ \\ ${ }^{1}$ Department of Materials Science \& Engineering, Rutgers University, Piscataway, NJ 08854. \\ ${ }^{2}$ Energy Storage Research Group (ESRG), Rutgers University, North Brunswick, NJ 08902.
}

Positive electrodes for Li-ion batteries have been developed recently based on transition metal fluoride $\left(\mathrm{FeF}_{3}, \mathrm{FeOF}, \mathrm{FeF}_{2}, \mathrm{CuF}_{2} \ldots\right) / \mathrm{C}$ nanocomposites [1]. The high specific capacity in these materials is obtained by using all the oxidation states of the transition metal during the redox cycle. At the present time, the intermediate phases that are formed during lithiation (discharge) are not well understood. In this study, we have used Scanning Transmission Electron Microscope (STEM) combined with EELS spectroscopy to determine the Li spatial distribution and its chemical state.

This STEM-EELS analysis was done with a JEOL 2010F equipped with a Gatan GIF 200 spectrometer. In order to minimize electron beam damage, the samples were cooled to $\mathrm{LN}_{2}$ temperatures and with a maximum electron dose of about $10^{4} \mathrm{C} / \mathrm{cm}^{2}$. Both lithiated (discharged) and de-lithiated (re-charged) $\mathrm{FeOF} / \mathrm{C}$ nanocomposites electrodes were analyzed and compared with possible conversion materials such as $\mathrm{LiF}, \mathrm{Li}_{2} \mathrm{O}$ and $\mathrm{Li}_{2} \mathrm{CO}_{3}$ which might form after lithiation. The carbon $\pi^{*}$ at $284 \mathrm{eV}$ was used for energy calibration.

The low loss EELS signals for the discharged and charged samples are shown in Fig 1 with the $\mathrm{Li}-\mathrm{K}$ edge for the standard $\mathrm{LiF}, \mathrm{Li}_{2} \mathrm{O}$ and $\mathrm{Li}_{2} \mathrm{CO}_{3}$ material. The $\mathrm{Li}$ edge has two prominent peaks whose energies and separation are summarized in Table 1 altogether with published data [2-5]. The separation of Li $K$ edge will be the key factor to identify the corresponding Li containing phases present in the electrode.

As expected, the re-charged electrode does not contain any $\mathrm{Li}$ and the low loss signal is composed of only the Fe-M edge. For the discharge electrode, the low loss signal is composed of the superposition of the Li-K edge and Fe-M edge. An enlarged view of the low loss edges for the lithiated $\mathrm{FeOF} / \mathrm{C}$ electrode is shown in Figure 2. In addition to the two prominent $\mathrm{Li}$ peaks with $\Delta \mathrm{E}=6.6 \mathrm{eV}$, there is a third one located at a distance of $4.2 \mathrm{eV}$ from the first Li peak. The existence of these peaks is indicative of the presence of two Li-base compounds. Possible phases are $\mathrm{LiF}$ and $\mathrm{Li}_{2} \mathrm{O}$ but a new lithiated iron oxide phase ( $\left.\mathrm{Li}-\mathrm{Fe}-\mathrm{O}\right)$ is also possible.

Further work in under way to determine quantitatively the content of the two Li compounds by linear combination fitting technique and to spatially resolve each phase. A preliminary result is shown in Figure 3 representing a DF STEM image (Fig 3a) with the corresponding EELS map of Li-K/Fe-M signal intensity ratio (Fig 3b).

\section{References}

[1] G.G. Amatucci and N. Pereira, J. Fluorine Chem. 128 (2007) 243

[2] A. Hightower, C.C. Ahn and B. Fultz, Appl. Phys. Lett. 77 (2000) 238.

[3] V. Mauchamp et al. Phys. Rev. B 74 (2006) 115106.

[4] N. Jiang and J.C. H. Spence Phys. Rev. B 69 (2004) 11511.

[5] H. Mizota et. al. AIP Conf. Proc. 882 (2007) 508.

[6] This research is supported by NECCES a DOE-BES-EFRC funded center. Special thanks also to IAMDN for the use of electron microscopy facility. 


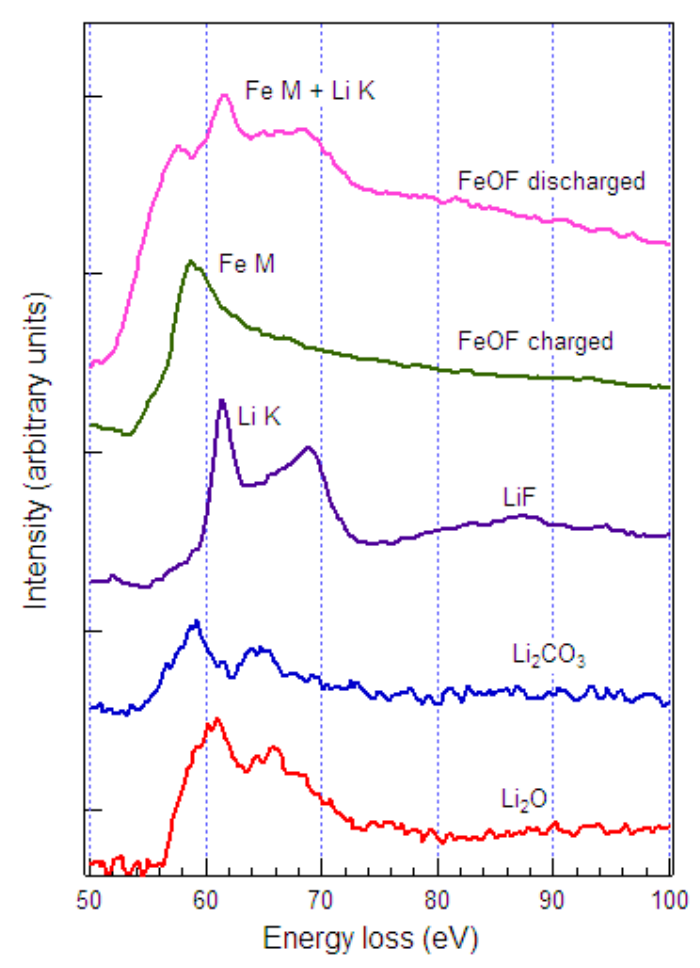

Figure 1: Li K-edge EELS spectra of $\mathrm{Li}_{2} \mathrm{O}$, $\mathrm{Li}_{2} \mathrm{CO}_{3}$, LiF, lithiated $\mathrm{FeOF} / \mathrm{C}$ and delithiated $\mathrm{FeOF} / \mathrm{C}$ nanocomposites

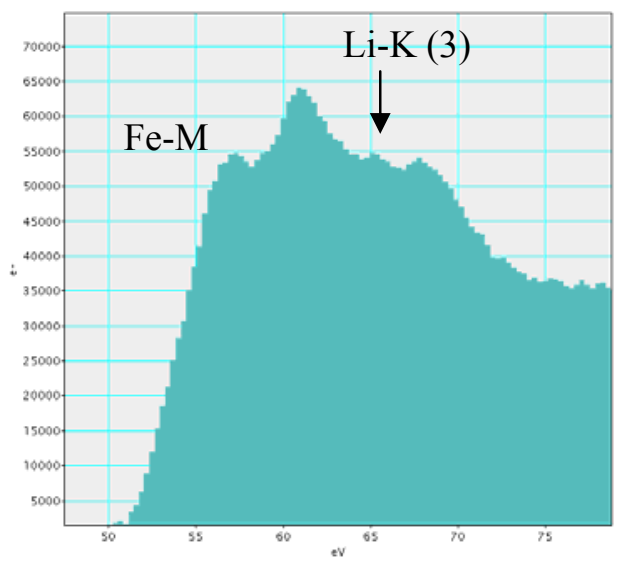

Figure 2: Fe-M and Li K-edges from lithiated $\mathrm{FeOF} / \mathrm{C}$ with small $\mathrm{Li}-\mathrm{K}$ neak 3

\begin{tabular}{|c|c|c|c|c|}
\hline \multirow{2}{*}{ Material } & \multicolumn{2}{|c|}{$\mathrm{Li} \mathrm{K}[\mathrm{eV}]$} & \multicolumn{2}{c|}{$\Delta[\mathrm{eV}]$} \\
\cline { 4 - 5 } & \multicolumn{2}{|c|}{} & Exp & $\begin{array}{c}\text { Literature } \\
{[2-5]}\end{array}$ \\
\hline $\mathrm{Li}_{2} \mathrm{O}$ & 61.1 & 65.6 & 4.5 & 4.7 \\
\hline $\mathrm{Li}_{2} \mathrm{CO}_{3}$ & 59.3 & 64.7 & 5.4 & 5.2 \\
\hline $\mathrm{LiF}$ & 61.0 & 68.4 & 7.4 & 7.0 \\
\hline $\begin{array}{c}\mathrm{FeOF} \\
\text { discharge }\end{array}$ & 61.5 & 68.1 & 6.6 & \\
\hline
\end{tabular}

Table 1: Position and separation of Li K-edges shown in the Figure 1 with comparison to literature data.
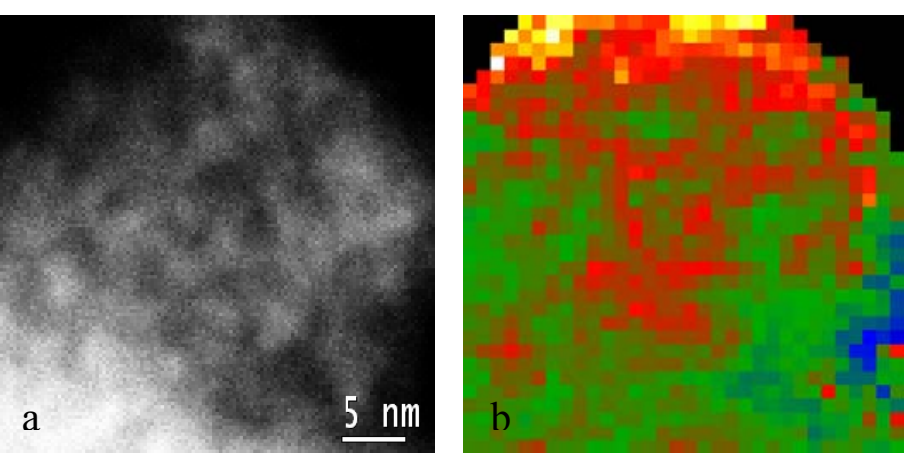

Figure 3. (a) DF-STEM image and (b) the corresponding EELS map of Li-K/Fe-M signal intensity ratio 